BOFF, P.; DEBARBA, J.F.; SILVA, E.; WERNER, H. Qualidade e sanidade de mudas de cebola em função da adição de composto termófilo. Horticultura Brasileira, Brasília, v.23, n.4, p.875-880, out-dez 2005.

\title{
Qualidade e sanidade de mudas de cebola em função da adição de com- posto termófilo
}

\author{
Pedro Boff'; João F. Debarba²; Edson Silva²; Hernandes Werner ${ }^{2}$ \\ ${ }^{1}$ EPAGRI - Est. Exp. de Lages, C. Postal 181 88502-970 Lages-SC; E-mail: pboff@epagri.rct-sc.br; ${ }^{2}$ EPAGRI - Est. Exp. de Ituporanga, \\ C. Postal 121, 88400-000 Ituporanga-SC
}

\begin{abstract}
RESUMO
Avaliou-se, em condições de campo, a influência de composto termófilo como adubação de base e em cobertura de canteiros, na sanidade e na qualidade de mudas de cebola. A semeadura foi realizada em maio e junho de 1993 e de 1994. Três experimentos foram delineados em blocos ao acaso, com seis repetições, tendo como tratamentos as adubações de base por composto termófilo, incluindo descarte de cebola; por formulação comercial organo-mineral; e por composição NPK. Em outro experimento, a adubação mineral e o composto termófilo foram combinadas em esquema fatorial com seis densidades de semeadura, tendo três repetições. Para a cobertura das sementes no leito de canteiros, foram avaliados num quinto experimento, o pó-de-serra de Pinus novo, pó-de-serra de Pinus com um ano, solo e composto termófilo, em delineamento de blocos ao acaso, com quatro repetições. A adubação por composto apresentou maior emergência e sobrevivência de mudas do que a adubação organo-mineral e mineral, nos três experimentos estudados. Independentemente da densidade de semeadura, o composto termófilo, como adubação de base, proporcionou maior sobrevivência de mudas $\left(101,4 \mathrm{pl} / \mathrm{m}^{2}\right)$ e menor intensidade de ataque de Botrytis squamosa $(51,7 \%)$, em comparação com adubação mineral $\left(85,7 \mathrm{pl} / \mathrm{m}^{2} \mathrm{e}\right.$ $56,8 \%$ ). Quando usado em cobertura das sementes, o composto propiciou maior emergência $\left(146,1 \mathrm{pl} / \mathrm{m}^{2}\right)$ e sobrevivência de mudas $\left(134,8 \mathrm{pl} / \mathrm{m}^{2}\right)$ do que a cobertura com terra $\left(90,2\right.$ e $77,5 \mathrm{pl} / \mathrm{m}^{2}$, respectivamente). Não houve influência, entre os tipos de adubação de base e/ou de cobertura, na ocorrência do tombamento de plântulas de cebola.
\end{abstract}

Palavras-chave: Allium cepa, Botrytis squamosa, tombamento, adubo orgânico, produção de mudas.

\begin{abstract}
Quality and health of onion seedlings by adding thermophilic compost

The effect of thermophilic compost on onion diseases and seedling quality used as basic fertiliser or bed cover was evaluated. The research was carried out in 1993 and 1994 in Ituporanga, Santa Catarina State, Brazil. Three experiments were conducted in randomised blocks with six replicates. The treatments were thermophilic compost, mineral fertilizer and organic-mineral fertilisers. In another experiment, the compost and the mineral fertiliser were combined with six plant densities in a factorial design experiment. For the seed bed coverage, new and one-year-old Pinus sawdust, soil, and thermophilic compost were evaluated using a randomised block design with four replicates. Thermophilic compost showed higher emergence and survival of onion transplants than organic-mineral and mineral fertiliser. The thermophilic compost increased the survival of onion transplants $\left(101.4 \mathrm{pl} / \mathrm{m}^{2}\right)$ and reduced Botrytis squamosa intensity (51.7\%) when compared with the mineral fertiliser $\left(87.7 \mathrm{pl} / \mathrm{m}^{2}\right.$ and $\left.56.8 \%\right)$ regardless of plant density. Onion seedlings grown on seedbeds covered with compost presented higher emergence $\left(146.1 \mathrm{pl} / \mathrm{m}^{2}\right)$ and survival of seedlings $\left(134.8 \mathrm{pl} / \mathrm{m}^{2}\right)$ than those grown using only soil as coverage $\left(90.2\right.$ and $77.5 \mathrm{pl} / \mathrm{m}^{2}$, respectively). The occurrence of damping-off did not differ between treatments with fertilisers alone or treatments in which coverage was used in the seedbed.
\end{abstract}

Keywords: Allium cepa, Botrytis squamosa, damping-off, organic fertiliser, transplants.

\section{(Recebido para publicação em 12 de maio de 2004 e aceito em 5 de julho de 2005)}

A cultura da cebola (Allium cepa $\mathrm{L}$ ), nas principais regiões de cultivo no Brasil, tem se caracterizado pelo uso intensivo do solo, emprego crescente de agroquímicos e poucas práticas culturais que possam oferecer sustentabilidade ao sistema produtivo (EPAGRI, 2000). Em Santa Catarina por exemplo, o controle das principais doenças da cebola, que vinha sendo feito com duas a três aplicações de fungicidas, passou a receber nos últimos 10 anos, mais de 15 intervenções no mesmo ciclo de cultivo (dados não publicados). Este aumento no uso de agrotóxicos é decorrente, em grande parte, da expansão da cultura em monocultivo, do estreitamento genético das cultivars comerciais e do próprio efeito negativo que estes agrotóxicos e a abusiva adubação mineral de alta solubilidade causam à flora e fauna local (GONÇALVES, 2001). A supressão de doenças e pragas em plantios comerciais, pode ser vista como manifestação da estabilidade e saúde do agroecossistema (THURSTON, 1992). Portanto, o restabelecimento da saúde solo-planta, em termos de conferir resiliência ao agroecossistema em resposta a distúrbios, é de fundamental importância na redução da necessidade de uso de agroquímicos (VAN BRUGGEN; SEMENOV, 2000).
No sul do Brasil, as principais doenças na cultura da cebola são a queimaacinzentada (Botrytis squamosa) e o míldio (Peronospora destructor) na fase de muda, ao passo que na fase pós-transplante, as mais freqüentes são o próprio míldio e a mancha-púrpura (Alternaria porri) (BOFF, 1996). A sanidade da muda de cebola durante o período de canteiro afeta diretamente o desenvolvimento da cultura no pós-transplante, visto que a necrose e morte de folhas nesta fase, reduz o tamanho de bulbo e enfraquece a qualidade de película dos mesmos para o armazenamento (BOFF, 1994).

Tem-se verificado que solos enriquecidos com matéria orgânica, via adubo 
verde, propiciam plantas de cebola tolerantes ao ataque de doenças e pragas, conferindo maior resistência de bulbos durante o armazenamento. A influência da adubação na ocorrência de doenças em plantas tem sido amplamente discutida e particularmente estudada por alguns autores na adição de compostos orgânicos (HOITINK; FAHY, 1986; PAULITZ; BAKER, 1987; HUBER, 1994; ELAD; SHTIENBERG, 1994). Huelsman e Edwards (1998) observaram que a adição de esterco compostado de gado reduziu, significativamente, a incidência de bacterioses (Pseudomonas syringae pv. lachrymans e Erwinia tracheiphila) em pepino e da antracnose (Colletotrichum piperatum) em pimentão, quando comparado à adição de adubo mineral nas proporções equivalentes de macronutrientes.

Mecanismos envolvidos na promoção de saúde de plantas, via adição de composto, incluem o estímulo da atividade antagonista local ou adicionada pelo composto, a indução de resistência e o efeito trófico na planta (HOITINK; FAHY, 1986; ZHANG et al., 1996; RAUPP, 1999). McQuilken et al. (1994) estudando a ação do extrato aquoso de esterco de gado com palha na atividade de Botrytis cinerea em alface, observaram redução da severidade desta doença, sugerindo estarem envolvidos mecanismos de antibiose e indução de resistência.

O efeito de resistência sistêmica adquirida, definida como aquela capaz de expressar-se distante do sitio inicial quando exposto ao indutor ou agente externo, sem afetar o DNA gemônico da planta, é de particular interesse no controle de doenças da parte aérea de plantas, via manejo de adubação (VAN LOON et al., 1998; MÉTRAUX et al., 2000). Os agentes de indução por sua vez, podem ser microorganismos, agentes físicos ou substâncias químicas capazes de despertar resistência do hospedeiro a uma larga gama de patógenos. Por outro lado, o potencial supressivo e a indução de resistência por compostos orgânicos é influenciado pelo processo de compostagem e pelo nível de maturação (HOITINK; FAHY, 1986).

No Estado de Santa Catarina, o sistema de cultivo de cebola utiliza-se de mu- das transplantadas. O ciclo de cultivo é relativamente longo e a colheita coincidente com a entrada de cebola da Argentina, obrigando o armazenamento dos bulbos por um período de até quatro meses (EPAGRI, 2000). A ocorrência de períodos chuvosos na época de colheita obriga o armazenamento dos bulbos, muitas vezes em condições precárias, resultando em grandes perdas (BOFF, 1996). O material advindo do descarte e da subseqüente toalete na comercialização dos bulbos é composto de escamas, raízes, folhas secas e bulbos deteriorados. É hábito do produtor de cebola, depositar este material em barrancas de rios, beiras de estradas ou outros locais longe de lavouras, pelo tradicional argumento de que restos culturais trariam doenças aos próximos cultivos de cebola. Não obstante esta prática possa ser justificada, a reciclagem local dos restos de descarte de cebola pelo processo de compostagem poderia oferecer uma melhor alternativa, não só em temos econômicos mas também sob ponto de vista ambiental. Quando o processo de compostagem for do tipo termófilo, alcançando temperaturas de até 70 ou $80^{\circ} \mathrm{C}$, há uma redução substancial de estruturas de patógenos e insetos-praga presentes nos restos culturais (GALUEKE, 1972; HOITINK; FAHY, 1986). Por outro lado, o composto oriundo do processo termófilo possibilita enriquecimento biológico, pela colonização de micro-organismos benéficos nos sucessivos revolvimentos da pilha. Do ponto de vista nutricional, o uso de composto orgânico para adubação de plantas propicia disponibilização gradativa e contínua de nutrientes sem haver excesso e/ou consumo de luxo, favorecendo o metabolismo da proteossíntese e minimizando com isto o ataque de doenças e pragas (CHABOUSSOU, 1980; SCHELLER, 2001).

O objetivo do presente trabalho foi estudar o efeito do composto termófilo resultante do descarte de bulbos na adubação de base e em cobertura de sementeiras e os possíveis efeitos desta técnica na sanidade e na qualidade de mudas de cebola.

\section{MATERIAL E MÉTODOS}

Conduziram-se cinco experimentos de campo na Estação Experimental da
Epagri, Ituporanga, durante a fase de muda da cebola, nos anos de 1993 e 1994, em Cambissolo álico.

Foram instalados três experimentos em épocas distintas de semeadura (maio/ 93, junho/93 e junho/94) utilizando-se blocos ao acaso com seis repetições. Nos três experimentos, os tratamentos constaram de três tipos de adubação de base nas seguintes modalidades: a) Adubação mineral, na dosagem de $300 \mathrm{~g} / \mathrm{m}^{2}$ de NPK (fórmula 5-20-10), incorporada ao solo 10 dias antes da semeadura; b) Adubação organo-mineral, formulação comercial "Prochnov", Trombudo Central (SC), na dosagem de $3 \mathrm{~L} / \mathrm{m}^{2}$ incorporada 10 dias antes da semeadura. Nesta formulação utiliza-se cama de aviário e $20 \%$ de complemento mineral de NPK (2-2-2); c) Adubação com composto $\left(10 \mathrm{~L} / \mathrm{m}^{2}\right)$ oriundo da compostagem termófila. Este composto foi elaborado com capim Cameroon (Pennisetum purpureum) triturado, esterco bovino e descarte de cebola triturado (1:1:1, base em volume), intermediada por finas camadas de cinza-de-arroz (combustão incompleta da casca de arroz), na proporção de $5 \%$ do total do composto e de calcário dolomítico, sendo este último espalhado na quantidade de $100 \mathrm{~g} / \mathrm{m}^{2}$, em duas secções horizontais da pilha. O composto foi revolvido aos 35 e 70 dias, sendo utilizado após 120 dias a partir da formação da pilha. Para o ano de 1993, utilizou-se a cultivar de cebola "Bola precoce", na semeadura de maio, e a população "Crioula", na semeadura de junho. No ano de 1994, com semeadura em junho, utilizou-se a população "Crioula".

Outro experimento com semeadura em junho de 1994, foi conduzido em delineamento de blocos ao acaso, com três repetições e em arranjo fatorial, utilizando-se a população "Crioula". Os fatores principais foram densidade e tipo de adubação. $\mathrm{O}$ fator densidade teve os níveis de 1,$0 ; 2,0 ; 2,5 ; 3,0 ; 4,0$ e 5,0 gramas de semente por metro quadrado e o fator adubação, em duas formas de adubação de base: composto e adubação mineral, nas mesmas proporções dos experimentos acima descritos. Não houve aplicação de fungicida para possibilitar avaliação da intensidade de queima-acinzentada. 
Tabela 1. Número de plantas emergidas (EM), tombadas (TO), remanescentes após tombamento (ES), sobreviventes até a época de transplante (SO) e peso fresco em gramas por planta $(\mathrm{PF})$ de mudas de cebola submetidas a diferentes tipos de adubação de base. Ituporanga, EPAGRI, 1993/94.

\begin{tabular}{|c|c|c|c|c|c|c|}
\hline $\begin{array}{l}\text { Época de } \\
\text { semeadura }\end{array}$ & Adubação base & $E M^{1 /}$ & $\mathrm{TO}^{2 l}$ & $\mathrm{ES}^{3 /}$ & $\mathrm{SO}^{4 l}$ & $\mathrm{PF}^{5 /}$ \\
\hline & Composto & 203,1 a & $9,5 \mathrm{~ns}$ & 194,2 a & 194,0 a & 3,2 a \\
\hline \multirow[t]{4}{*}{ Maio/93 } & Organo-min. & $179,1 b$ & 11,9 & 177,6 a & 177,5 a & $2,6 \mathrm{~b}$ \\
\hline & Mineral & $171,4 \mathrm{~b}$ & 2,4 & $116,9 \mathrm{~b}$ & $116,7 \mathrm{~b}$ & $2,4 \mathrm{~b}$ \\
\hline & C.V. & 12,4 & 131 & 15,4 & 16,5 & 23,7 \\
\hline & Composto & 222,6 a & $0,8 \mathrm{~ns}$ & 218 a & 221,4 a & $4,1 \mathrm{~b}$ \\
\hline \multirow[t]{4}{*}{ Junho/93 } & Organo-min. & $197,4 a b$ & 2,6 & 194 a & $189,5 a b$ & $5,6 a b$ \\
\hline & Mineral & $191,5 \mathrm{~b}$ & 1,2 & $184 a$ & $166,8 \mathrm{~b}$ & 5,7 a \\
\hline & C.V. & 14,5 & 100 & 16,2 & 24,8 & 25,1 \\
\hline & Composto & 138,7 a & $2,3 \mathrm{~ns}$ & $134 a$ & 124 a & $3,5 \mathrm{~b}$ \\
\hline \multirow[t]{3}{*}{ Junho/94 } & Organo-min. & $119,1 \quad b$ & 1,8 & 118 a & $111 \mathrm{ab}$ & 4,4 a \\
\hline & Mineral & $122,9 \quad b$ & 4,3 & $114 b$ & $99 \quad b$ & $3,7 a b$ \\
\hline & C.V. & 10,1 & 59,3 & 12,2 & 17,1 & 25,4 \\
\hline
\end{tabular}

*Médias seguidas pela mesma letra, na vertical, dentro de cada época de semeadura, não diferem entre si (Tukey, 0,05).; $n s=$ diferenças não significativas.

Um quinto experimento foi conduzido em blocos ao acaso com quatro repetições, utilizando-se a cultivar "Bola Precoce", com semeadura em maio de 1994. Os tratamentos constaram de quatro coberturas sobre o leito dos canteiros, na espessura de $2 \mathrm{~cm}$, onde as sementes eram previamente semeadas, que foram: a) composto, já descrito acima; b) solo, do próprio local; c) pó-de-serra de Pinus, do ano; d) pó-de-serra de Pinus, com um ano de idade. Utilizou-se, como adubação de base, $300 \mathrm{~g} / \mathrm{m}^{2}$ de adubo mineral NPK, fórmula 5-20-10.

A profundidade de semeadura foi de $2 \mathrm{~cm}$, utilizando-se como cobertura da semente o pó-de-serra de Pinus, exceto no quinto experimento, onde o objeto de estudo foi o tipo de cobertura. O controle de plantas daninhas foi manual. A irrigação foi feita conforme necessidade da cultura, sendo, no máximo, uma vez por semana. As parcelas constaram de $3 \mathrm{~m}^{2}$, tendo como área útil $1 \mathrm{~m}^{2}$. Avaliou-se o número de plantas emergidas, número de plantas tombadas, número de folhas cotiledonares (chicote) tombadas e número de plantas remanescentes após tombamento (estande). Por ocasião do transplante, avaliou-se também o número de plantas sobreviventes, o peso fresco e seco de plantas. A queimaacinzentada foi avaliada, semanalmente, até 15 dias antes do arranquio das mudas, estimando-se a proporção de área foliar necrosada pela doença con- forme metodologia modificada de Stuker e Boff (1998). A ocorrência da queima-acinzentada foi estimada considerando-se o número de folhas totais, a altura média de folhas e a proporção de área foliar necrosadas devido aos sintomas da doença, em quatro sub-amostras não destrutiva de $0,25 \mathrm{~m}^{2}$ por parcela. As sub-amostras eram delimitadas com auxílio de um quadriculado de madeira $(0,5 \times 0,5 \mathrm{~m})$ lançado aleatoriamente em cada avaliação. Dados coletados de todos os experimentos foram submetidos à análise de variância para cada tipo de delineamento, blocos ao acaso ou fatorial, com auxílio do pacote estatístico $\mathrm{SAS}^{\circledR}$, seguido de teste de médias Tukey $(0,05)$, quando o valor de $\mathrm{F}$ fosse menor ou igual a 0,05 . A não interação entre adubação e densidade no experimento em arranjo fatorial permitiu análise independente desses fatores. Os dados das características avaliadas em função da densidade foram submetidos à regressão múltipla e modelos de equação foram selecionados pelo seu maior coeficiente de determinação encontrado.

\section{RESULTADOS E DISCUSSÃO}

A aplicação do composto termófilo proporcionou maior emergência e sobrevivência de mudas até o transplante, em comparação com adubação mineral, nas três épocas de semeadura da cebola estu- dadas (Tabela 1). A adubação organomineral não diferiu da adubação mineral, em todas as características consideradas, exceto no número de mudas remanescentes após o tombamento nos experimentos com semeadura em maio de 1993 e junho de 1994 e no número de mudas sobreviventes até o transplante, no experimento com semeadura em maio de 1993. Shiau et al. (1999) relataram que certos compostos orgânicos, formulação comercial FBN-5 $\mathrm{A}^{\hat{a}}$ por exemplo, quando adicionada a substratos promoveram melhor desenvolvimento de plantas de repolho, tanto em casa de vegetação como em plantios comerciais, além de serem efetivos no controle de Rhizoctonia solani. No quarto experimento com semeadura em junho de 1994 não houve interação, entre o tipo de adubação e a densidade de semeadura da cebola. No fator adubação, observou-se que a adubação mineral e o composto termófilo não diferiram na emergência de plantas, no peso da massa fresca ou seca produzida e no tombamento (Tabela 2). Entretanto, canteiros enriquecidos pelo composto apresentaram maior sobrevivência de plantas até o transplante. Em contraste, canteiros adubados organicamente, mesmo apresentando maior densidade de plantas sobreviventes, foram menos atacados por B. squamosa. Sabe-se que o fungo $B$. squamosa tem sua principal forma de sobrevivência como escleródios 


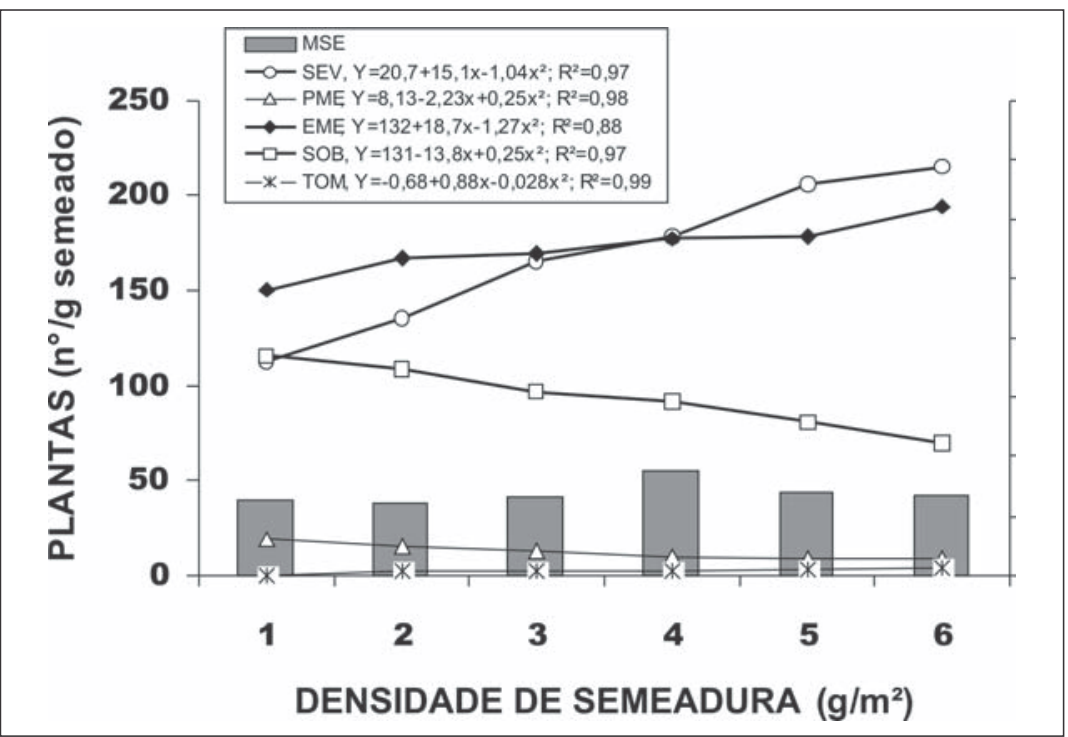

Figura 1. Massa seca (MSE), severidade por Botrytis squamosa (SEV), peso médio por planta (PME), Emergência (EME), sobrevivência (SOB), tombamento de plântulas (TOM) de mudas de cebola submetidas a diferentes densidades de semeadura. Ituporanga, EPAGRI, 1994.

Tabela 2. Emergência (EM), sobrevivência (SO), peso fresco (PF), massa seca (MS), severidade da queima-acinzentada (SE) e tombamento (TO) de mudas de cebola submetidas a aplicação de composto termófilo e adubação mineral. Ituporanga, EPAGRI, 1994.

\begin{tabular}{lcccccc}
\hline Adubação & $\mathbf{E M}^{1 /}$ & $\mathbf{S O}^{2 /}$ & $\mathbf{P F}^{3 /}$ & $\mathbf{M S}^{4 /}$ & $\mathbf{S E}^{5 /}$ & $\mathbf{T O}^{6 /}$ \\
\hline Composto & $170,9 \mathrm{~ns}$ & $101,4 \mathrm{a}^{*}$ & $4,61 \mathrm{~ns}$ & $14,9 \mathrm{~ns}$ & $51,7 \mathrm{~b}^{*}$ & $1,3 \mathrm{~ns}$ \\
Mineral & $174,3 \mathrm{~ns}$ & $85,7 \mathrm{~b}$ & $4,12 \mathrm{~ns}$ & $12,9 \mathrm{~ns}$ & $56,8 \mathrm{a}$ & $2,9 \mathrm{~ns}$ \\
\hline CV & 20,1 & 28,10 & 60,1 & 53,0 & 16,8 & 124,7 \\
\hline
\end{tabular}

*Médias seguidas pela mesma letra na vertical não diferem entre si $(\mathrm{F}=0,05)$; $n s=$ diferenças não significativas.

em restos culturais, sendo também a fonte primária de inóculo entre ciclos de cultivo (BOFF, 1994). A adição de composto que possivelmente possibilitou o aumento da atividade antagonista na rizosfera pôde ter reduzido a viabilidade das estruturas de resistência deste fungo (PEREIRA et al., 1996). De fato, Walker e Maude (1975) observaram que os escleródios de Botrytis spp sofrem naturalmente antagonismo por Gliocladium roseum, especialmente em solos ricos em matéria orgânica.

$\mathrm{O}$ aumento da densidade de semeadura de 1 para $5 \mathrm{~g} / \mathrm{m}^{2}$ reduziu gradativamente a sobrevivência e o peso médio de mudas, independentemente do tipo de adubação utilizada (Figura 1). Os produtores de cebola, no sistema corrente de transplante, utilizam altas densidades, acima de $3 \mathrm{~g} / \mathrm{m}^{2}$, com o propósito de melhor aproveitamento da área supressivo nas doenças, mas também melhorou substancialmente a qualidade de mudas para plantios comerciais. No presente trabalho, o tombamento de plântulas não diferiu entre as coberturas, embora o tombamento da folha chicote foi maior na cobertura por pó-deserra de ano e por composto. A análise de amostras de plântulas e folhas tombadas não apresentou presença de fitopatógenos, indicando ser o problema de origem abiótica. Sua ocorrência esteve relacionada com altas precipitações nos dias anteriores à avaliação (Dados não apresentados). Provavelmente, a alta umidade no leito do canteiro favoreceu o enfraquecimento da axila foliar, facilitando o tombamento da lâmina foliar (chicote).

Houve tendência da cobertura por composto ser melhor que o pó-de-serra de ano e este melhor que o pó-de-serra novo, quanto à emergência, estande e sobrevivência de mudas. O composto termófilo pode ter proporcionado maior estabilidade biológica por não demandar suprimento de nutrientes, principalmente, nitrogênio, como estaria acontecendo com a cobertura por pó-de-serra, cujo material necessita passar por um processo de estabilização biológica (GALUEKE, 1972). Nesta cobertura por pó-de-serra, a atividade microbiana requer suprimento extra de nutrientes, a fim de iniciar a decomposição da matéria orgânica, o que vem a desequilibrar o desenvolvimento inicial da plântula de cebola (SCHELLER, 2001).

$\mathrm{O}$ maior teor de massa seca e maior sobrevivência de plantas (Tabelas 2 e 3 ) e a menor intensidade da queimaacinzentada (Tabela 2) proporcionado pela adubação de base ou cobertura por composto pode estar relacionado, no seu conjunto, com os mecanismos de suprimento equilibrado de nutrientes e de resistência induzida à patógenos (PEREIRA et al.,1996; SCHELLER, 2001; RAUPP, 1999). Segundo Chaboussou (1987), adubos com fontes nitrogenadas de alta solubilidade, como os formulados minerais N-P-K, deixam a planta em estado de proteólise dominante, aumentando as substâncias solúveis, principalmente aminoácidos, que favorecem o parasitismo por fungos. A qualidade de mudas pode ainda ser influenciada pela 
Tabela 3. Emergência (EM), tombamento de plântulas (TOp), tombamento da folha cotiledonar (TOfc), estande após tombamento (ES), sobrevivência de plantas por ocasião do transplante (SO), massa seca (MS) e peso fresco (PF) de mudas de cebola submetidas a diferentes coberturas de conteiros. Ituporanga, EPAGRI, 1994.

\begin{tabular}{|c|c|c|c|c|c|c|c|}
\hline Cobertura & $\mathrm{EM}^{1 /}$ & TOp ${ }^{2 l}$ & TOfc $^{3 l}$ & $\mathrm{ES}^{4 l}$ & $\mathrm{SO}^{5 /}$ & MS $^{6 /}$ & $\mathrm{PF}^{71}$ \\
\hline Composto & $146,1 \quad a$ & 4,3 & $50,4 a$ & 135,3 a & 134,8 a & $11,7 \mathrm{~ns}$ & $5,1 \mathrm{~ns}$ \\
\hline Terra & $90,2 \mathrm{~b}$ & 6,6 & $17,6 \mathrm{~b}$ & $77,8 \mathrm{~b}$ & $77,5 \mathrm{~b}$ & 10,8 & 3,4 \\
\hline Pó-de-serra novo & 135,2 a & 7,1 & $34,2 \mathrm{~b}$ & $109,3 a b$ & $101,8 \mathrm{ab}$ & 10,1 & 4,1 \\
\hline Pó-de-serra de ano & $141,1 \mathrm{a}$ & 9,2 & $36,8 a b$ & $108,3 a b$ & $106,1 \mathrm{ab}$ & 9,7 & 3,6 \\
\hline$\overline{C . V .}$ & 7,1 & 34,8 & 14,5 & 11,8 & 15,6 & 8,5 & 17,5 \\
\hline Dias após semeadura & 30 & 33 & 35 & 40 & transplante & $=$ & $=$ \\
\hline
\end{tabular}

* Médias seguidas pela mesma letra, na vertical não diferem entre si (Tukey, 0,05 ); $n s=$ diferenças não significativas.

micorrização, cuja adição de compostos orgânicos facilita o estabelecimento desta associação simbiótica, com rápida resposta na cultura da cebola (LINDERMAN, 1989).

De modo geral, conclui-se que o composto termófilo utilizado, incluindo descarte de cebola, utilizado como adubação de base ou em cobertura de canteiro, propiciou mudas de cebola mais resistentes/tolerantes ao ataque de Botrytis squamosa e maior sobrevivência de plantas para o transplante. É possível que os produtores de cebola possam obter mudas de melhor qualidade e que respondam a melhores produções de bulbo, pelo uso da adubação orgânica, oriunda do processo de compostagem termófila. Além disso, o maior teor de massa seca das mudas produzidas em solos enriquecidos por compostagem, pode influir na melhor conservação de bulbos, visto estar relacionado com o teor de sólidos solúveis que é o principal parâmetro utilizado na avaliação de conservação dos mesmos (EPAGRI, 2000). Não se verificou, neste trabalho, a transmissão de patógenos da cebola através do composto, que pudesse inviabilizar a inclusão de palha e bulbos descartados no processo da compostagem termófila. Assim, o emprego do processo termófilo de compostagem pode viabilizar a reciclagem adequada de descarte de cebola em vista de dar maior sustentabilidade ao sistema de cultivo, pois propicia destino adequado deste descarte, reduz os riscos da fonte de inóculo de patógenos oriundos dos restos culturais e possibilita o aumento da matéria orgânica favorecendo o enriquecimento da biodiversidade do solo.

\section{AGRADECIMENTOS}

Os autores agradecem a colaboração de Adriana Campos e de Marcelo Pitz nas atividades de laboratório e de campo, respectivamente.

\section{LITERATURA CITADA}

BOFF, P. O complexo Botrytis spp, causando doenças em cebola. Revista Agropecuária Catarinense, Florianópolis, v.7, n.13, p.14-16, 1994.

BOFF, P. Levantamento de doenças na cultura da cebola, em Santa Catarina. Fitopatologia Brasileira, Brasília, v.21, n.1, p.110-114, 1996

BOFF, P.; STUKER, H.; GONÇALVES, P.A.S. Influência da densidade de plantas na ocorrência de doenças foliares e produção de bulbos de cebola. Horticultura Brasileira, Brasília, v.23, n.4, p.448-452, 1998.

CHABOUSSOU, F. Les Plants Malades dês Pesticides; bases nouvelles d'une prevention contre maladies et parasites. Paris: Ed. Debard, 1980. $270 \mathrm{p}$

ELAD, Y.; SHTIENBERG, D. Effect of compost water extracts on grey mould (Botrytis cinerea). Crop Protection, v.13, n.2, p.109-114, 1994.

EPAGRI. Sistemas de produção para cebola. Florianópolis: Epagri, 2000. 91 p.

GALUEKE, C.G. Composting; a study of the process and its principles. Pennsylvania, EUA: Rodale Press, 1972. $110 \mathrm{p}$.

GONÇALVES, P.A.S. Impacto de adubações mineral e orgânica sobre a incidência de tripes, Thrips tabaci Lind., e míldio, Peronospora destructor Berk. Casp., e da diversidade vegetal sobre tripes e sirfídios predadores em cebola, Allium cepa $L$. São Carlos, UFSCar, 2001. 123 f. (Tese doutorado)

HOITINK, H.A.J.; FAHY, P.C. Basis for the control of soilborne plant pathogens with composts. Annual Review of Phytopathology, v.24, p.93-114, 1986.

HUBER, D.M. The influence of mineral nutrition on vegetable disease. Horticultura Brasileira, Brasília, v.12, n.2, p.206-214, 1994.
HUELSMAN, M.F.; EDWARDS, C.A Management of disease in cucumbers (Cucumis sativus) and pappers (Capsicum annum) by using composts and fertility inputs. In: BRIGHTON CROP PROTECTION CONFERENCE: Pests \& Diseases, 3. 1998, Brighton, UK. Proceedings ... Farnham, UK: BCP Council, 1998. p.881-886.

LINDERMAN, R.G. Organic amendments and soil-born diseases. Canadian Journal of Plant Pathology, v.11, n.1, p.180-183, 1989.

McQUILKEN, M.P.; WHIPPS, J.M.; LYNCH, J.M. Effects of water extracts of a composted manure-straw mixture on the plant pathogen Botrytis cinerea. World Journal of Microbiology and Biotechnology, v.10, n.1, p.20-26, 1994.

MÉTRAUX, J.P.; NAWRATH, C.; GENOUD, T. Systemic acquired resistance. In: INTERNATIONAL SYMPOSIUM OF DURABLE DISEASE RESISTANCE: KEY TO SUSTAINABLE AGRICULTURE, 2000, Ede, NL. Book of abstracts... Wageningen, NL: WAU, 2000, p.24.

PAULITZ, T.C.; BAKER, R. Biological control of Pythium damping-off of cucumbers with Pythium nunn: influence of soil environment and organic amendments. Phytopathology, v.77, n.2, p.341-346, 1987.

PEREIRA, J.C.R.; ZAMBOLIM, L.; RIBEIRO DO VALE, F.X.; CHAVES, G.M. Compostos orgânicos no controle de doenças de plantas. Revisão Anual de Patologia de Plantas, Passo Fundo, v.4, p.353-379, 1996.

RAUPP, J. Fertilization systems in organic farming based on long-term experiments. Darmstadt, Germany: Institute for Biodynamic Research, 1999. 62 p. (EU report, project. AIR3CT94-1940)

SCHELLER, E. Fundamentos científicos da nutrição vegetal na agricultura ecológica. Trad. B.T. Sixel. Botucatu: ABD, 2001. 78 p.

SHIAU, F.L.; CHUNG, W.C.; HUANG, J.W.; HUANG, H.C. Organic amendment of commercial culture media for improving control of Rhizoctonia damping-off of cabbage. Canadian Journal of Plant Pathology, v.21, n.2, p.368-374, 1999.

STUKER, H.; BOFF, P. Tamanho da amostra na avaliação da queima-acinzentada em canteiros de cebola. Horticultura Brasileira, Brasília, v.16, n.1, p.10-13, 1998.

THURSTON, H.D. Sustainable practices for plant disease management in traditional farming systems. Colorado, USA: Westview Press, 1992. $279 \mathrm{p}$. 
Van BRUGGEN, A.H.C.; SEMENOV, A.M. In search of biological indicators for soil health and disease suppression. Applied Soil Ecology, v.15, n.1, p.13-24, 2000.

Van LOON, L.C.; BAKKER, P.A.H.M.;

PIETERSE, C.M.J. Systemic resistance induced

by rhizosphere bacteria. Annual review of phytopathology, v.36, p.453-483, 1998.
WALKER, J.A.; MAUDE, R.B. Natural occurrence and growth of Gliocladium roseum on the mycelium and sclerotia of Botrytis allii. Transaction of the British Mycological Society, v.65, n.2, p.335-337, 1975.
ZHANG, W.; DICK, W.A.; HOITINK, H.A.J. Compost-induced acquired resistance in cucumber to Pythium root rot and anthracnose. Phytopathology, v.86, n.10, p.1066-1070, 1996. 